NBER WORKING PAPER SERIES

\title{
ORGANIZATIONAL SCOPE AND INVESTMENT: EVIDENCE FROM THE DRUG DEVELOPMENT STRATEGIES AND PERFORMANCE OF BIOPHARMACEUTICAL FIRMS
}

\author{
Ilan Guedj \\ David Scharfstein \\ Working Paper 10933 \\ http://www.nber.org/papers/w10933
}

\author{
NATIONAL BUREAU OF ECONOMIC RESEARCH \\ 1050 Massachusetts Avenue \\ Cambridge, MA 02138 \\ November 2004
}

We are grateful to Thomas Roberts, M.D. and Stan Finkelstein for collaborating with us in collecting the Phase I clinical trials data. We also appreciate their insights into the clinical trials process. Catherine Chang, Stephanie Sherman, Jimmy Sun, and Athanasios Vorvis provided exceptional research assistance. We thank Pierre Azoulay, Malcolm Baker, Patrick Bolton, Evan Beckman, Murillo Campello, Amy Hutton, Josh Lerner, Sendhil Mullainathan, Oguzhan Ozbas, Gary Pisano, Antoinette Schoar, Daniel Scharfstein, and Jeremy Stein for helpful discussions, seminar participants at Columbia, Dartmouth, Illinois, NBER, and Princeton for their comments. This research was supported by grants from the National Science Foundation, Harvard Business School Division of Research, and the Program on the Pharmaceutical Industry at MIT.The views expressed herein are those of the author(s) and do not necessarily reflect the views of the National Bureau of Economic Research.

(C) 2004 by Ilan Guedj and David Scharfstein. All rights reserved. Short sections of text, not to exceed two paragraphs, may be quoted without explicit permission provided that full credit, including () notice, is given to the source. 
Organizational Scope and Investment: Evidence from the Drug Development Strategies and Performance of Biopharmaceutical Firms

Ilan Guedj and David Scharfstein

NBER Working Paper No. 10933

November 2004

JEL No. G3, L2, O31, O32

\begin{abstract}
$\underline{\text { ABSTRACT }}$
This paper compares the clinical trial strategies and performance of large, established ("mature") biopharmaceutical firms to those of smaller ("early stage") firms that have not yet successfully developed a drug. We study a sample of 235 cancer drug candidates that entered clinical trials during the period 1990-2002 and were sponsored by public firms. Early stage firms are more likely than mature firms to advance drug candidates from Phase I to Phase II clinical trials. However, early stage firms have much less promising clinical results in their Phase II trials and their Phase II drug candidates are also less likely to advance to Phase III and to receive Food and Drug Administration approval. This pattern is more pronounced for early stage firms with large cash reserves. The evidence points to an agency problem between shareholders and managers of single-product early stage firms who are reluctant to abandon development of their only viable drug candidates. By contrast, the managers of mature firms with multiple products in development are more willing to drop unpromising drug candidates. The findings appear to be consistent with the benefits of internal capital markets identified by Stein (1997).

\author{
Ilan Guedj \\ MIT \\ Sloan School of Management \\ guedj@mit.edu \\ David Scharfstein \\ Harvard Business School \\ Morgan 493 \\ Soldiers Field \\ Boston, MA 02163 \\ and NBER \\ dscharfstein@hbs.edu
}




\section{INTRODUCTION}

How does organizational scope affect investment behavior and performance? We study this question by examining the drug development behavior and performance of biopharmaceutical firms. We believe that drug development is an ideal setting in which to address this question for three reasons. First, there is considerable heterogeneity in how biopharmaceutical firms are organized. Some are well-established firms with many drugs on the market and a large portfolio of drug candidates at various stages of development. Others are early stage firms with no products yet on the market and no more than one or two drugs in development. Second, there is a wealth of detailed, publicly available information on the project-level investments of biopharmaceutical firms, namely the clinical trials required by the U.S. Food and Drug Administration (FDA) to determine the safety and efficacy of drug candidates. Finally, these investments have measurable outcomes. Thus, one can compare, at a very fine-grained level, the investment behavior and performance of firms that differ in their organizational scope.

Why might we expect the scope of an organization to affect its investment behavior and performance? Our hypothesis is a variant of Stein (1997) who identifies the conditions under which an internal capital market that allocates funds across $n$ competing projects is preferable to an external capital market that funds $n$ single-project firms. In his framework, the problem with single-project firms is that when they have poor investment opportunities they may still invest because their managers will be reluctant to return funds to shareholders and lose the private benefits that come from running firms and projects. This is less of a problem in an internal capital market because managers 
have a broader range of projects in which to invest, allowing them to get both private benefits and better projects.

This basic logic fits closely with the biopharmaceutical industry. The biggest investments in this industry are the clinical trials that are required for a drug to be approved by the Food and Drug Administration (FDA). ${ }^{1}$ A particular drug candidate must go through three phases of clinical trials on human subjects: small Phase I trials designed in most cases to test a drug's safety; larger Phase II trials to test both its safety and efficacy; and finally very large Phase III trials with as many as a several thousand subjects. At each point along the way, a company must decide based on scientific, clinical, and financial information whether to continue to the next, more expensive phase of clinical trials.

We argue that the managers of early-stage biopharmaceutical firms --- those with only one or two drugs in development --- are excessively reluctant to end clinical trials after Phase I. Pulling the plug then would mean either that the firm would have to be liquidated or that research on a new drug would have to be started. If the firm is liquidated, the managers would lose the private benefits that come from running the company. These private benefits are best thought of as firm-specific human capital. If the firm is not liquidated, but instead a new research program is begun to replace the failed one, the managers might also lose private benefits to the extent that their human capital is tied to the abandoned research program. Therefore, we argue that managers of early-stage firms would be willing to take marginally uneconomic projects forward from Phase I to Phase II.

\footnotetext{
${ }^{1}$ The most recent estimate of the cost of getting a single drug approved is $\$ 802$ million (deflated to 2000). This estimate factors in the expected costs associated with failed attempts to develop a drug.
} 
This sort of problem is less severe in mature biopharmaceutical firms with numerous drug candidates in pre-clinical and clinical testing. The managers who make the decision to move a Phase I trial into Phase II choose among a portfolio of drug candidates. While they may benefit from moving drugs along in the pipeline, it is unlikely that they benefit disproportionately from any particular drug being advanced. Thus, we would expect them to choose to advance drugs with the highest value to the company. This is the essence of Stein's (1997) argument on the value of internal capital markets.

This perspective suggests that: (1) early-stage firms will be more aggressive in taking trials from Phase I to Phase II; (2) early-stage firms will be more likely to have unpromising clinical results at Phase II; and (3) early stage firms are less likely to take a trial forward from Phase II to Phase III.

Financial constraints could mitigate the tendency of early stage firms to be overly aggressive in moving forward from Phase I to Phase II. To the extent that firms lack the cash reserves to fund Phase II trials, we would expect them to be less prone to move forward and, conditional on moving forward, to have better clinical results. These low cash, early-stage firms would therefore also be more likely to move forward from Phase II trials to Phase III.

Our empirical results are in line with these predictions. The sample we analyze consists of 235 Phase I trials for drugs to treat cancer. We find that early-stage firms are more prone than mature firms to advance into Phase II trials within two years of initiating their Phase I trial (61.4\% vs. 45.3\%). Moreover, if an early stage firm advances to Phase II, the clinical results of the Phase II trial are worse. In Phase II trials conducted by early 
stage firms, the percentage of patients exhibiting some shrinkage of their tumors --- a key marker of success of a Phase II trial --- is less than half that of trials conducted by mature firms (6\% vs. 12\%). Given the poor performance of Phase II trials sponsored by early stage firms, it is not surprising that these firms are also much less likely than mature firms to move into Phase III trials within a three-year period (13.6\% vs. $34.9 \%)$. This difference is driven to a very large extent by early stage firms with large cash reserves. These firms bring $75.6 \%$ of their Phase I trials into Phase II, and have an even lower tumor response rate in Phase II (4\% vs. $12 \%$ for mature firms). Only $3.2 \%$ of the Phase II drug candidates of high-cash early stage firms proceed to Phase III (i.e. once in 31 Phase II trials). Low-cash, early stage firms are only slightly more prone than mature firms to go from Phase I to Phase II, have somewhat worse clinical results in Phase II trials, and are less likely to proceed to Phase III.

These results point to agency problems in external capital markets that lead to over-investment. They suggest that internal capital markets play a role in mitigating these over-investment problems (Stein, 1997) and that large cash reserves exacerbate the extent of over-investment (Jensen, 1986).

Our findings connect in important ways to three literatures. The first is the literature on the costs and benefits of internal capital markets. Much of this literature suggests that internal capital markets lead to investment inefficiencies due to crosssubsidization of divisions in low-growth industries by those in high growth industries (Scharfstein and Stein, 2000, Scharfstein, 1998, Shin and Stulz, 1998 and Rajan, Servaes and Zingales, 2000). Another line of the empirical literature argues that internal capital 
markets enable firms to redeploy capital from unprofitable sectors to more profitable ones (Khanna and Tice, 2001, and Maksimovic and Phillips 2002).

This paper is also related to the literature on free cash flow and investment (Jensen, 1986) claiming that firms with large cash flows, cash reserves, or debt capacity, tend to over-invest. There are many papers that try to test this hypothesis, but the ones closest to ours are those that look at investments at the project level. Lang, Stulz and Walkling (1991) find that the stock price reaction to the announcement of an acquisition is smaller when bidding firms have excess cash flow. More recently, Bertrand and Mullainathan (2003) find that firms with excess cash flow tend to bid more for oil and gas leases and that these leases are, on average, less productive.

Finally, our paper is related to the literature on the determinants of success in drug development. The closest link is to Danzon, Nicholson, and Pereira (2003) who estimate the effect of experience on the probability that firms move forward in the clinical trials process. They find that small firms are slightly more likely than large firms to advance from Phase I to Phase II, and that the effect is reversed for Phase II to Phase III transitions. They interpret these findings as evidence that there is learning-by-doing in the management of clinical trials; however, our findings suggest that the higher Phase II success rates of large firms may not be the result of learning-by-doing but rather may be the result of agency problems at small firms that lead them to bring poor drug candidates into Phase II trials. ${ }^{2}$

\footnotetext{
${ }^{2}$ Cockburn and Henderson (2001) examine the determinants of success at the level of a research program (e.g. cardiac and circulatory) rather than at the level of a particular drug candidate. They find that firms with a broader range of research program are more likely to end up with FDA-approved drugs. Given the different unit of analysis it is difficult to link their results to ours.
} 
The paper is organized as follows. The next section outlines a simple framework to structure our thinking about the agency problems that arise in biopharmaceutical firms. Section 3 outlines the construction of the database and Section 4 presents the results. Section 5 concludes.

\section{A SIMPLE FRAMEWORK}

This section outlines a very simple framework for comparing the investment behavior of early-stage biopharmaceutical firms to that of mature biopharmaceutical firms. We model the decision of whether to advance from a Phase I clinical trial, the earliest and least expensive phase of clinical development, to a Phase II clinical trial. Based on the results of the Phase I trial, the manager assesses the probability that a Phase II trial will be "successful," and that he would want to go forward to Phase III. "Successful" is in quotation marks because a clinical trial does not really "succeed" or "fail." Rather, the results are often difficult to interpret, with reasonable people differing on the interpretations. For simplicity, however, we suppose that if the trial is successful, further development of the drug has an expected discounted payoff of $X>0$. If the trial is unsuccessful the expected payoff is zero. Let $p_{2}$ be the probability of success. Let $I_{2}$ be the cost of conducting a Phase II trial. Finally, suppose that $A$ is the liquidation value of the compound if it does not advance to Phase II. Then, the first-best decision rule is to go forward to Phase II provided:

$$
p_{2} X-I_{2} \geq A
$$


Would an early stage firm use this decision rule? We argue that the answer is no because the managers (or founders) of early stage firms derive private benefits, $b$, from their projects. In this case, the condition would be

$$
p_{2} X-I_{2}+b \geq A
$$

As a result, an early stage firm would be more prone to advance to Phase II than would be implied by the first-best condition (1).

What are the managers' private benefits in the context of drug development? One possibility is that managers have project-specific human capital that they would lose if they abandon the project and try to develop another drug. A second possibility is that managers have firm-specific human capital that they would lose if they abandon the project and the firm is liquidated. Finally, one can interpret $b$ as a measure of managerial over-optimism about the expected payoffs from the project.

Like the managers of early stage firms, the managers of drug development projects in mature firms are also likely to derive private benefits from drug development. However, unlike early stage firms, the decision of whether to advance to Phase II is not made by these managers, but rather higher-level managers who choose among a portfolio of drug candidates. These managers might derive private benefits from drug development, but there is no reason to believe that they derive benefits from one particular project over another. Thus, if they cannot choose to undertake all of the projects, they will choose those with the highest expected value exclusive of private benefits. This is essentially Stein's (1997) argument for the efficiency of internal capital markets. 
This simple framework generates two empirical predictions. From a comparison of (1) and (2) we get the first prediction.

Prediction 1: Early stage firms will be more likely to advance from Phase I trials to Phase II trials.

Holding $X$ and $I_{2}$ fixed, a comparison of (1) and (2) implies that early stage firms that go ahead to Phase II, will do so, on average, at lower levels of $p_{2}$. This generates a second prediction:

Prediction 2: Early stage firms will be more likely to fail in Phase II clinical trials.

There are additional predictions if financial constraints are introduced into the model. These are most relevant for early stage firms, as mature firms have large cash flows from existing drugs on the market. If early stage firms do not have the financial resources to fund a Phase II trial, they will have to finance the trial by raising external capital. If the project has negative net present value this will be difficult or impossible to do. If the firm has cash, $C$, it will have to raise $I_{2}-C$, and will only be able to raise outside capital if $p_{2} X-I_{2}>-C$. If $C$ is small, the firm will not be able to fund projects with significant negative net present value. Thus, we have our third and fourth predictions.

Prediction 3: Early stage firms with low cash reserves will be less likely to advance from Phase I to Phase II trials than early stage firms with high cash reserves.

Prediction 4: Early stage firms with low cash reserves will be more likely to succeed in Phase II trials. 


\section{DATA}

In order for a drug to be marketed, the FDA requires that it go through a series of clinical trials on human subjects. Phase I trials --- the earliest and smallest of the clinical trials --- are typically conducted on fewer than 30 patients, are designed to determine a drug's safety. For most diseases, these trials are performed using healthy subjects, although cancer drug trials, the focus of our study, are conducted on subjects with the disease. DiMasi et. al. (2003), using a sample of 68 drug candidates in clinical trials at large pharmaceutical firms between 1983 and 1994, estimate that the mean (median) outof-pocket cost of a Phase I trial was \$15.2 million (\$13.9 million) deflated to 2000.

Phase II trials are larger and more costly than Phase I trials. They include as many as a few hundred subjects, use patients with the disease, and are designed to test both safety and efficacy. The mean (median) cost of a Phase II trial in the DiMasi et. al. sample was \$23.5 million (\$17.0 million).

Finally, Phase III trials are typically very large studies, including possibly thousands of subjects. The mean (median) cost of a Phase III trial in the DiMasi sample was $\$ 86.3$ million ( $\$ 62.0$ million). After completing these trials, a drug sponsor can seek regulatory approval from the Food and Drug Administration by filing a New Drug Application (NDA) ${ }^{3}$.

The analysis focuses on clinical trials for the treatment of cancer. There are a few reasons why we restrict attention to cancer. First, one can only make meaningful comparisons of clinical outcomes within a disease class. The outcome of a clinical trial for lung cancer (e.g. tumor response) cannot easily be compared to the outcome of a

\footnotetext{
${ }^{3}$ For certain classes of drugs, a drug's sponsor will file a Biological License Application, which is also evaluated by the FDA.
} 
clinical trial for hypertension (e.g. reduction in blood pressure). Second, in the case of cancer, there are relatively straightforward, measurable clinical outcomes such as tumor response. Third, as noted above, Phase I cancer trials include sick patients so that, in principle, efficacy can be measured at an early stage. We conjectured that Phase I cancer trials might result in more useful clinical information that could inform a decision to move to Phase II. (As we will soon see, this did not turn out to be the case.) Finally, cancer is the disease class with the largest number of clinical trials during the last decade.

\subsection{Sample Construction}

The starting point for the construction of our sample is a database we assembled in conjunction with Thomas Roberts, M.D. The database includes the Phase I clinical oncology trials described in annual volumes of Papers/Proceedings of the American Society of Clinical Oncology from 1990-2002. Each year, the American Society of Clinical Oncology (ASCO) has an annual meeting for its members, mainly medical clinicians and researchers. Coinciding with the meeting, ASCO publishes (in hard copy and now on-line) a compilation of abstracts describing research in the field. It is standard for oncology research groups to submit abstracts describing their research. These abstracts are not peer-reviewed, and all submitted abstracts are published.

Phase I trials are identified by searching all the abstracts that include in their title or in the abstract itself the words "Phase I", "Phase I/II", "dose-finding", "new", and "novel". From this list, only the ones that indeed describe a Phase I clinical trial are kept. Abstracts that describe one or more of the following are excluded: combination trials (i.e. trials using multiple drug compounds); agents targeting pediatric cancers; agents that 
were previously reviewed by the FDA; radiation therapies or immuno-therapies; herbal medication; supportive care; and trials on non-human subjects. Combination therapies are excluded because it is very difficult to determine how successful a clinical trial is when a compound is tested in conjunction with another given that it is hard to determine the baseline response rate of the other compound. It also makes sense to exclude agents targeting pediatric cancers because the approval process for these drugs is quite different. Agents previously reviewed by the FDA add to the complexity of the data collection and therefore are excluded. The other trials are excluded because they are not drugs per se. More details about the sample can be found in Roberts et. al. (2004).

Table 1 provides information on the annual number of abstracts describing Phase I oncology trials in the database and lists the annual number of abstracts excluded for each reason. The main reason for exclusion is that the trial is a combination therapy. There are a total of 2,798 Phase I abstracts identified, but only 1,180 abstracts describe agents that meet the criteria. These 1,180 abstracts describe 377 drug agents. ${ }^{4}$ There are more abstracts than agents both because there are multiple abstracts published to describe a single trial, and because there are multiple Phase I trials on a single drug agent. Not surprisingly, there is a general increase over time in the number of abstracts and agents meeting the selection criteria.

The identity of the organization sponsoring the trial was collected from two commercial databases: Thomson's Investigational Drug Database (IDdb) and PJB Publications' PharmaProjects. The sponsors are a combination of public companies $(62.3 \%)$, private companies $(27.6 \%)$, universities and government agencies $(10.1 \%)$.

\footnotetext{
${ }^{4}$ There are 351 unique drug agents in the sample, but there are 26 instances where a particular agent is being developed by two different organizations for different indications.
} 
$58.9 \%$ of the Phase I trials are conducted by firms with headquarters in the United States. Many of the foreign companies in our sample, such as Novartis and Elan Pharmaceuticals, are listed on U.S. stock exchanges and have significant research operations in the U.S. If the drug is being developed as part of an alliance between two organizations, we follow PharmaProjects in only counting the sponsor that developed the agent and is sponsoring the trial. There are several cases in which there are equal cosponsors of the trials and we drop these from the sample. We have 175 unique sponsors in the sample.

Our analysis centers on the 235 Phase I trials undertaken by the public firms in our database. We exclude the 65 drug candidates sponsored by private firms at this point because it is difficult to get balance sheet data on these firms, and because these firms raise issues, such as the role of venture capital, that are beyond the scope of this paper. We use Thomson Financial's Thomson Research (formerly Global Access) to find the tickers of the public companies, their IPO dates and financial details of the IPO. We merge it with Standard \& Poor's Compustat, Compustat Canada, and Compustat Global Industrial/Commercial in order to get financial data about the public companies in our sample. For comparability, all the financial numbers are converted to U.S. Dollars and then adjusted to U.S. Dollars for the year 2000.

The PharmaProjects database also track compounds through their stages of development, from as early as pre-clinical laboratory studies to FDA approval. Thus, we were able to reconstruct the timeline of development including follow-on clinical trials in Phase II and Phase III. We also collected information from this database on the kinds of 
cancer the trials were targeting, ${ }^{5}$ the market size of the indication being targeted, and the pharmacological properties of the drug candidate. The last of these describes a drug's mechanism of action in the body, through which it exerts its therapeutic effect, i.e. it identifies the biological agent or process the drug stimulates or inhibits. This information will be useful to us in constructing measures of the novelty of a particular drug candidate.

\subsection{Information on Clinical Trials}

Our study focuses on four aspects of clinical development: the decision of the company to take the project forward from Phase I to Phase II; the clinical outcome of the Phase II study; the decision to move from Phase II to Phase III; and ultimate FDA approval. Table 2 provides information on the time between the initiation of the first Phase I trial and the initiation of the first Phase II trial, as well as the time between Phase II and Phase III trials. Panel A indicates that the average time between Phase I and Phase II trials is 25.3 months. Panel B shows that $65 \%$ of the Phase 1 trials move forward within two years and $80 \%$ do so within three years (Table 3, Panel B). ${ }^{6}$ This is about twice as long as the time between initiation of Phase I and Phase II trials reported in DiMasi et. al. (2003).

The mean time between initiation of the first Phase II trial and first Phase III trial is 27.1 months (Table 2, Panel A), with almost $60 \%$ moving forward within two years and $76 \%$ moving forward within three years (Table 2, Panel B). The mean length between trials is comparable to numbers reported in the DiMasi study.

\footnotetext{
${ }^{5}$ Note that Phase I oncology trials do not typically target a specific cancer while Phase II trials do.

${ }^{6}$ Based on this distribution, in some of our regression analyses we will look at the decision to move to Phase II within two years following the first announcement of Phase I.
} 
Of course, not all trials move forward to the next phase. As Table 2, Panel C shows, $67 \%$ move forward from Phase I to Phase II as compared to $71 \%$ in the DiMasi study. Note however that our sample is right censored; for Phase I trials begun later in the sample, there are only a few years during which the trial could have moved forward. Given that the lion's share of Phase I trials move forward within three years, this right censuring of Phase II trials is not a major issue. Table 2, Panel C also shows that $32 \%$ of the trials that make it to Phase II, later move forward to Phase III. DiMasi's study finds that $44 \%$ of the Phase II trials move forward to Phase III. Here the right censuring might be more of an issue, because the time between Phase I and Phase III is four to five years. ${ }^{7}$

Beginning in Phase II, drug candidates are tested for particular indications, e.g., lung cancer, liver cancer, or breast cancer. As Table 3, Panel A shows, 54\% of the agents are tested for two or more cancers, with the mean being 2.7 indications. In a majority of cases $(57 \%)$, sponsors only have one agent in clinical trials in our sample, while two sponsors (Bristol Myers Squibb and Novartis) show up sixteen times. The average is 2.1 agents.

\subsection{Information on Companies}

Table 4 presents summary data (deflated to the year 2000) on the public companies sponsoring the trials in the sample. On average, the public companies are very large, with mean revenues of over $\$ 8$ billion, mean assets of almost $\$ 11$ billion, mean cash of close to $\$ 2$ billion and mean $R \& D$ of about $\$ 1$ billion. The average market

\footnotetext{
${ }^{7}$ As our study will show, the Phase II to Phase III probabilities depend on the type of firm that is undertaking the trial and the DiMasi study is restricted to mature biopharmaceutical firms. Also, the transition probabilities and mean time between trials are very similar for public firms and the rest of the sample.
} 
capitalization is over $\$ 38$ billion and mean $\mathrm{Q}$ is 10.2 . On average, the firms were public for almost 26 years before embarking on the Phase I trials in our sample.

These averages mask considerable heterogeneity in the data. The $25^{\text {th }}$ percentile firm has revenues of only $\$ 9.5$ million, cash of $\$ 41.4$ million, $R \& D$ of $\$ 21.0$ million and a market capitalization of $\$ 202.7$ million. As we have suggested, there are really two types of firms that are undertaking clinical trials in oncology. One type is the mature biopharmaceutical firm with sizable revenues, some (or many) drugs already on the market, and a portfolio of drug candidates in clinical trials or in the laboratory. The other type of firm is an early stage biopharmaceutical, with no drugs on the market and a limited portfolio of drug candidates (often only one) in clinical trials or in the laboratory.

Because we do not have direct information on drug revenues by company, our proxy for whether a firm is early stage is whether the firm has revenues less than $\$ 30$ million deflated to 2000. The revenues of these firms typically come from two sources: milestone payments from other firms as part of alliances and contract R\&D work. There are a few firms with revenues greater than $\$ 30$ million, but less than $\$ 250$ million. We found that these firms all had drugs that were on the market or about to be on the market, so we consider them mature firms.

Panels B and C of Table 4 break out the sample into mature and early stage firms. Fifty-nine percent of the Phase I trials are done by mature firms, and the remainder are done by early stage firms. Not surprisingly, the differences between these firms are very large in terms of cash, $\mathrm{R} \& \mathrm{D}$, and market capitalization. 


\section{EMPIRICAL ANALYSIS}

In this section we compare the decisions of early stage and mature firms to move forward in the clinical trials process.

\section{A. Basic Analysis}

A. 1 Phase I to Phase II Transition Probabilities. We start by estimating probit models of the decision to go from Phase I to Phase II within two years. We use a twoyear cutoff on the Phase II decision for two reasons. One reason is that, without a cutoff, Phase I trials that were begun in the early part of the sample would be more likely to be taken forward. If there is an over-representation of one type of firm in the early period, this would bias our findings. The second reason to use a time cutoff is to measure the aggressiveness with which firms move forward in the clinical trials process. Note that $69 \%$ of the agents that are taken forward to Phase II by the public companies are taken forward within two years. To avoid making seemingly arbitrary cutoffs, we will also estimate Cox proportional hazard models. This allows us to estimate the probability per year that a firm takes a trial forward.

The key regressor in our model is, Early Stage, a dummy variable for whether the drug's sponsor is an early stage biopharmaceutical firm. We also include a set of controls: information on the clinical outcome at Phase I --- response rate and toxicity; whether the drug is a biologic agent (as opposed to a chemical compound); whether the drug was sponsored at one point by the National Institutes of Health or any of its affiliate organizations; the novelty of the agent under investigation; and the potential market size of the drug. 
Before getting to the regressions it is worth simply comparing the Phase II transition probabilities of the early stage and mature firms. Of the 139 agents sponsored by mature firms, 63 (45.3\%) move from Phase I to Phase II within two years. By contrast, early stage firms are more prone to advance to Phase II; of the 96 agents sponsored by early stage firms, 59 (61.4\%) move forward to Phase II within two years. This difference is statistically significant at the $1 \%$ confidence level.

The probit regressions in Table 5 show that this finding is robust to the inclusion of various controls. The reported numbers are the marginal effects of a unit increase in the regressors, not coefficient estimates from the regression. The first column just replicates the finding discussed above without the controls: the estimated marginal effect of the Early Stage dummy is 0.161 , indicating that early stage firms are $16.1 \%$ more likely than mature firms to move forward to Phase II.

The second column of Table 5 adds Phase I clinical data to the regression, but the Early Stage estimate is unaffected. An increase in the tumor response rate at Phase I from zero to $10 \%$ is predicted to increase the Phase II transition probability by $9.7 \%$. This estimate is, however, statistically insignificant. This is true of the other regressors as well. Whether the drug candidate is a biologic agent or a chemical compound has a small, statistically insignificant effect. Prior NIH-sponsorship of research on the drug candidate appears to have a large estimated effect on the probability of moving forward, but here too the estimate is statistically insignificant.

These results are consistent with the view that early stage companies are more aggressive in bringing drug candidates into Phase II trials because they derive private benefits from doing so and they, unlike mature firms, do not have a portfolio of other 
drug candidates to advance in clinical trials. An alternative explanation, however, is that early stage are attempting to develop drug candidates that would have higher payoffs if they succeed (a higher $\mathrm{X}$ in our model). In this case, they would use a lower breakeven success probability $\left(\mathrm{p}_{2}\right)$ in deciding whether to advance to Phase II. For example, early stage companies might be targeting particular cancers with a large market size where there are few other approved therapies. It is also possible that the drug candidates of early stage firms are more scientifically innovative and therefore would have a higher payoff if they were to succeed.

Column 3 of Table 5 reports results that address these possibilities by adding two controls to the regression. The first control is a set of two market size dummies that come from estimates in the PharmaProjects database. The first dummy is for whether the market size is between $\$ 500$ million and $\$ 2$ billion, and the second dummy is for whether the market size is greater than $\$ 2$ billion. The excluded dummy is for whether the market size is less than $\$ 500$ million. Although the estimated effects of these dummies are positive, they are not statistically significant. Given that an overwhelming majority of the drug candidates target a market size in the $\$ 500$ million to $\$ 2$ billion range, it is not a surprising finding. In addition, as noted earlier, most Phase I cancer trials target cancer in general, not specific cancers, so it is unlikely that there would be much variation in market size at the Phase I stage.

The last regression in Table 5 also includes a measure of the drug candidate's novelty. Novelty is calculated in the following way. As noted in Section 3, PharmaProjects contains a pharmacological description of each drug candidate. Thus, for each pharmacological description we rank drug candidates chronologically, with the 
$n$th drug candidate chronologically within a certain category getting the rank of $n$. A drug candidate with a higher $n$ is considered less novel. For example, in 1989, ScheringPlough was the first to conduct a clinical trial using a DNA antagonist (Tomozolomide). In 2000, Access Pharma also began clinical trials of a DNA antagonist, but it was the twentieth such clinical trial, making it less novel by our measure. The average $n$ in our sample of mature firms is 24.6 , while the average for early stage firms is 22.0 a statistically insignificant difference.

In the regression in column 3 of Table 5 , we include the natural $\log$ of $1 / n$ as our measure of novelty. There is a positive, statistically significant relationship between novelty and the probability of moving from Phase I to Phase II. Nevertheless, there is no appreciable effect of including the novelty measure on the Early Stage dummy. This is not surprising in light of the fact that there is little difference in the novelty of the drug candidates developed by early stage and mature firms.

A. 2. Performance of Phase II Trials. Prediction 2 suggests that early stage firms will be less successful than mature firms in Phase II trials. To test this prediction we collected data on the clinical outcomes of the Phase II trials from abstracts published in Papers/Proceeding the American Society of Clinical Oncology, the same source we used for information on the Phase I trials. We record the percentage of patients in a trial that exhibit some tumor shrinkage. This is a key endpoint used by the industry to measure the success of Phase II oncology trials. We have clinical data on a total of 201 Phase II trials. These include multiple trials conducted on a single agent for different indications. We are unable to find clinical information on a number of the trials that we know were 
initiated either because the study was not completed or because the study abstract was never published in Papers/Proceedings.

Table 6 presents summary information on the average tumor response rate reported in the Phase II trials undertaken by the firms in our sample. On average, the tumors of $9.5 \%$ of trial participants showed some response. Consistent with our prediction, the table also shows that the response rate was nearly twice as high for the mature firms $(12.0 \%)$ as for the early stage firms (6.1\%). The table also shows the distribution of clinical trials across twelve different cancer types, with the most common being respiratory, digestive, breast, and genital type cancers. There is no systematic difference between mature and early stage firms in the distribution of trials across these cancer types. The table also shows the percentage of patients in the trials who received prior treatments for cancer. Again there is no difference between early stage and mature firms.

Table 7 compares the Phase II response rates of early stage and mature firms in a regression framework. The first column of the table restricts attention to the 108 Phase II trials begun within two years of the initiation of the Phase I trial for which we also have Phase II clinical data. This column includes no controls and simply documents that the average response rate in these trials is $4.4 \%$ lower for early stage firms than for mature firms. The difference is not statistically significant. Including the controls in the regression in the second column amplifies the difference; on average, early stage firms have a $5.9 \%$ lower response rate than mature firms. Evaluated at the means of the controls, this regression model predicts that the response rate of patients enrolled in Phase II trials of mature firms will be twice as likely to exhibit some tumor shrinkage as 
patients in Phase II trials of early stage firms. The third column of Table 7 shows that the estimated effect is similar if we include all Phase II trials, not just those begun within two years of Phase I initiation.

A. 3 Phase II to Phase III Transition Probabilities. Another measure of whether Phase II trials are successful is whether firms proceed to Phase III trials. Before discussing the regressions, it is useful to compare the mean transition rates for the two sets of firms. Of the 63 drug candidates brought to Phase II by mature firms within two years, $22(34.9 \%)$ are later brought to Phase III within three years. By contrast, only 8 (13.6\%) of the 59 drug candidates brought to Phase II trials within two years by early stage firms are eventually brought to Phase III trials within three years. This $21.3 \%$ differential is highly statistically significant.

Table 8 presents the regression analysis. The first column simply replicates the comparison that we just presented. The other columns add the standard controls, but none is statistically significant and they do not affect the estimated effect of the Early Stage dummy.

A.4. Current Status of the Drugs. Yet another measure of success is whether the drug candidate is ultimately approved by the FDA. In Table 10, we present the current status of the drugs. Panel A shows that $15 \%$ of the drugs of mature companies have been approved while only $6 \%$ of the drugs of early stage companies have been approved. In Panel B, we restrict the comparison to those drugs that had moved to Phase II in 2 years or less. The differences are amplified for this sub-sample. For the early stage firms, only $8.5 \%$ of the drug candidates were approved by the FDA, whereas for the mature firms, $28.6 \%$ were approved. This fact also supports the view that early stage firms are less 
selective in the drug candidates they bring forward to Phase II. One caveat to keep in mind, however, is that given the time is takes to get FDA approval, drugs that enter our sample relatively late will have a lower probability of getting approved. This will only explain the difference between early stage and mature firms if mature firms begin their trials earlier in the sample, but there is no evidence of that.

A.5. Sales Revenue. As noted earlier, it is possible that early stage firms are more likely to advance from Phase I to Phase II not because of agency problems, but because they have more novel therapeutic approaches and they are targeting larger markets. As we showed, this is not the case. Moreover, including measures of novelty and market size has no meaningful effect on the estimates.

Another way to see whether early stage firms are going after higher payoff projects is to look at their payoffs when they actually succeed in launching a drug. There are 29 product launches in our sample, only seven of which are by early stage firms. We were able to collect information on product sales in the first three years after the product launch for all seven launches by early stage firms and 17 of the 22 product launches by mature firms. The differences are quite striking, but are the opposite of what one would expect if early stage firms are taking bigger risks. As can be seen from Table 10, in each of the three years, the mature firms sell considerably more than the early stage firms. In the first year after launch, the sales of products launched by early stage firms are $\$ 12.7$ million on average as compared to $\$ 99.7$ million for mature firms. In the second year, the average is $\$ 61.3$ million for early stage firms as compared to $\$ 141.3$ million for mature firms. In the third year, early stage firms sell \$108.4 million, whereas mature firms sell \$204.3 million on average. 
In five instances, we were unable to find information on the sales of products by mature firms. One might be concerned that when sales are very low for such firms, this information is less likely to be disclosed. Even so, if one assumes that sales for these products are zero, the average sales of products launched by mature firms are still greater that those of early stage firms in each of the three years following product launch.

A. 6. Alliances. Many of the early stage companies in the sample develop their drug candidates as part of an alliance with a large pharmaceutical company. In these alliances a pharmaceutical firm typically makes payments to an early stage firm to fund clinical development in exchange for the right to license and sell the drug if it is approved. In our sample, $62.5 \%$ of the drug candidates of early stage companies have some kind of an alliance at the time of the Phase I trial. One might expect that the alliance limits the ability of an early stage company to take compounds forward from Phase I to Phase II if they have little chance of succeeding. This does not appear to be the case in our sample; there is very little difference in the transition probabilities of drug candidates being developed in alliances and those being developed solely by an early stage firm. This finding is consistent with Guedj (2004) who shows that mature pharmaceutical firms are more likely to advance Phase I clinical trials into Phase II when they are developing a drug in an alliance with an early stage firm than when they are developing a drug on their own.

\section{B. The Effect of Financial Resources on the Clinical Trials of Early Stage Firms}

The previous sub-section presents evidence that early stage firms are more prone than mature firms to move forward from Phase I to Phase II, to have worse clinical 
results in their Phase II trials (in the form of lower response rates), and to be less likely to move from Phase II to Phase III. Our model suggests that managers of early-stage firms are reluctant to pull the plug in early clinical trials even if doing so would be value maximizing. However, as Prediction 3 indicates, to the extent that the firm has fewer financial resources, this should put a limit on the ability of management to over-invest in Phase II trials and should lead to greater success at Phase II (Prediction 4).

To test these predictions, we need a measure of financial resources. We define a firm with limited financial resources as one with cash of less than $\$ 30$ million (deflated to 2000). Our assumption is that all mature firms have ample financial resources given that biopharmaceutical firms generate very large cash flows (even after their considerable R\&D expenses). Thus, the test really hinges on comparing the Phase I and Phase II decisions and outcomes of early stage firms based on their cash holdings.

A simple comparison of transition probabilities for early stage firms tells the basic story. Of the 96 Phase I trials conducted by early stage firms, 55 are conducted by firms with low cash reserves, and the remaining 41 are conducted by firms with relatively large cash reserves. Out of the 55 Phase I trials conducted by the low-cash firms, 28 (50.9\%) proceed to Phase II, whereas 31 (75.6\%) out of the 41 Phase I trials conducted by the high-cash firms proceed to Phase II. Thus, the Phase II transition probability for the lowcash early-stage firms is only slightly higher than that of mature firms (45.3\%), whereas the transition probability of the high-cash firms is significantly higher than those of the constrained early stage firms and the mature firms. This result is reflected in the probit regressions in Table 11. As before, none of the controls is statistically significant nor do they impact the estimated effects of Early Stage dummies. 
Table 12 shows that the average response rate of patients in Phase II trials conducted by high cash early stage firms is particularly low. In the full model with controls, the response rate of these firms is $9.3 \%$ below that of mature firms; the response rate of early stage low cash firms is $4.7 \%$ below that of mature firms. This basic pattern is robust to including all Phase II trials, not just those begun within two years of Phase I initiations. The estimated effects for the early stage high-cash firms are statistically significant. Evaluated at the means of the controls, they predict that patients enrolled in trials conducted by mature firms will be more than three times as likely to show some tumor shrinkage as patients enrolled in a study conducted by high-cash early stage firms.

The findings on the Phase II to Phase III transition are also very striking. Of the 28 Phase II trials conducted by low-cash firms, 7 (25.0\%) went on to Phase III; however, only $1(3.2 \%)$ out of the 31 Phase II trials conducted by high-cash firms went to Phase III. The Phase II success rate of the high-cash firms is obviously much lower than that of the low-cash firms and the mature firms (34.9\%). The success rate of the early stage constrained firms is lower than that of the mature firms, but the difference is not statistically significant. Again, these finding are reflected in the probit regressions, which are presented in Table 13.

\subsection{Estimating Proportional Hazard Models}

As discussed above, our data is right censored by which we mean that some drugs may eventually advance to Phase II or Phase III, but we do not yet observe that event. A Phase I trial begun in 2002 that has not yet transitioned to Phase II is not the same as a Phase I trial begun in 1994 that has not transitioned to Phase II. We dealt with this 
problem by counting as a Phase I to Phase II transition only those that occurred within two years. Likewise for Phase III transitions, we only counted those that occurred within three years of initiating Phase II. This approach has the added benefit of measuring how successful each phase was on the theory that trials that transition more quickly are probably more highly valued by their sponsors.

Another approach to dealing with right censoring is to use survival analysis. Survival analysis examines and models the time it takes for an event to occur. Here we use the Cox proportional hazard model, following the specification outlined in Cox (1975). A drug is assumed to have a certain probability of succeeding in each period. Success is defined as the event of moving from Phase I to Phase II. The instantaneous probability of success at any given time $t$ is called the hazard rate, $h(t)$, defined as:

$$
h(t)=\frac{\operatorname{Pr} \text { obability of success between } t \text { and } \Delta t}{\operatorname{Pr} \text { obability of success for times } \geq t}
$$

The Cox model assumes that the hazard function has the functional form:

$$
h(t)=h_{0}(t) \cdot e^{\beta_{1} x_{1}+\beta_{2} x_{2}+\ldots+\beta_{n} x_{n}}
$$

However, the model assumes no restriction on the function $h_{0}(t)$.

We report the results of our survival analysis in Table 14 . We use the same controls as in the previous section. The numbers reported are hazard ratios. In column 1, the estimated effect of being an early stage company is large and statistically significant; it indicates that early stage firms have a 58\% higher hazard of moving to Phase II than do mature firms. The second column breaks out high-cash and low-cash firms. Not surprisingly, the high-cash firms have an even higher hazard ratio; they are $123 \%$ more 
likely than mature firms to transition from Phase I to Phase II. The increased hazard for the low-cash firms is $24 \% \%$, but it is statistically insignificant.

Columns 3 and 4 describe a similar analysis, although in this case we measure the hazard of moving from Phase II to Phase III. The results on Phase II to Phase III transitions are similar to those discussed earlier. The hazard ratio for the early stage firms is 0.39 , indicating that their hazard of progressing from Phase II to Phase III is less than half that of mature firms. This estimate is statistically significant. The effects for the early stage high-cash firms and early stage low-cash firms are similar.

\section{CONCLUSION}

We show that early stage biopharmaceutical firms are more aggressive than mature biopharmaceutical firms in bringing their drug candidates forward from Phase I to Phase II clinical trials. However, the drug candidates they bring to Phase II appear to be less promising; conditional on making it to Phase II, patients in trials conducted by early stage firms are much less likely to show some tumor shrinkage and these drug candidates are much less likely to advance to Phase III. These findings are driven to a great extent by the sub-sample of early stage firms with large cash reserves.

Our findings point to an agency problem between shareholders and managers of single-product early stage firms who are reluctant to pull the plug on their only viable drug candidates. We argue that the interests of managers of mature firms are more aligned with their shareholders. With their large portfolio of drug candidates, managers of these firms are more willing to pull the plug on unpromising drug candidates because 
they have other ones they can bring to clinical trials. The findings appear to be consistent with the benefits of internal capital markets identified by Stein (1997).

There are a number of ways in which we hope to build on this research. First, it is worth investigating why there are big differences in the behavior of early stage firms. Part of the answer may lie in understanding why some firms have more cash on hand than others. One possibility is that firms are more prone to raise equity capital during periods when biopharmaceutical firms are more highly valued. These funds give managers considerable freedom in the conduct of clinical trials. By contrast, when market valuations in this sector are low, firms tend to rely more heavily on alliances in which control over clinical trials is shared by the firm and its alliance partner (Lerner, Shane and Tsai, 2003). Thus, understanding the role of the equity markets and alliances in the clinical trials process is very high on our research agenda. ${ }^{8}$

Second, we have ignored differences that may exist in the drug development strategies of mature firms. Although our evidence suggests that having more drugs in the pipeline makes firms more selective on average and results in a higher Phase II success rate, the composition of this pipeline and the organizational structure of these firms could have an effect on their decision making. For example, if cancer drugs are a large part of a company's overall portfolio, is it more or less selective in its decision to move forward to Phase II? Or if the drug candidate was acquired in a merger, how does it affect the transition probability?

Finally, it would be worth examining the 65 trials that are conducted by the private firms in our sample. We suspect that many of these firms are still being funded

\footnotetext{
${ }^{8}$ Guedj (2004) is a first step in understanding the role of alliances in clinical trials. His research suggests that even with alliances early stage firms are more prone to take drugs forward from Phase I to Phase II and the fail in Phase II trials.
} 
by venture capitalists. In theory, it is not clear whether the existence of venture capital funding exacerbates or mitigates the agency problem in drug development. On the one hand, venture capitalists fund companies in stages, disbursing funds only when they are needed. To the extent that venture capitalists are able to assess the prospects of the drug, they would not choose to fund drugs with low expected payoffs. On the other hand, the goal of venture capitalists may not be to maximize the value of the portfolio company, but rather the shorter-run probability that the firm can be taken public. Gompers (1996) has shown that this incentive is particularly strong among young venture capital funds with limited track records since they need to convince potential limited partners that they have made good portfolio investments. Thus, if a company is better able to go public if it has later stage clinical trials, venture capitalists may encourage early stage firms to move clinical trials forward even if the expected payoffs are low.

Our findings raise broader issues about the creation and survival of biopharmaceutical startups. If the $R \& D$ process in early stage firms is inefficient, as we suggest, then it is natural to ask why such firms would ever be created and how they could survive in parallel with mature biopharmaceutical firms that seem not to be plagued by these inefficiencies. Why wouldn't the founders of biopharmaceutical firms --- most of whom are academic scientists --- sell their ideas to mature firms with diverse product portfolios who can manage clinical development more efficiently? It is important to note that many of them do in fact sell their scientific discoveries to established firms. However, many do not because in doing so they give up control of follow-on scientific and clinical advances that emerge in the process of development. While a scientist could, in principle, be compensated for these follow-on discoveries, given the difficulty of 
writing complete contracts, it is unlikely that he would be compensated as much as if he retained control and developed the idea in his own firm. Thus, one potential benefit of founding a firm to commercialize a scientific discovery is that it provides high-powered incentives for discovery. The potential cost --- documented in our research --- is that it provides high-powered incentives to advance drugs through clinical trials even though it may be inefficient to do so. This suggests that there are costs and benefits of conducting scientific discovery within different organizational forms. A fuller understanding of these costs and benefits should be the goal of future research. 


\section{References}

Bertrand, Marianne and Sendhil Mullainathan, "Cash Flow and Investment Project Outcomes: Evidence from Bidding on Oil and Gas Leases," MIT working paper, 2003.

Cockburn, Iain, and Rebecca Henderson "Scale and Scope in Drug Development: Unpacking the Advantages of Size in Pharmaceutical Research." Journal of Health Economics, 20, 2001, pp.1033-1057

Danzon, Patricia, Sean Nicholson, and Nuno Sousa Pereira, "Productivity in Pharmaceutical-Biotechnology R\&D: The Role of Experience and Alliances," National Burea of Economic Research Working Paper No. 9615, March 2003.

DiMasi, Joseph A., Ronald W. Hansen and Henry G. Grabowski, "The Price of Innovation: New Estimates of Drug Development Costs," Journal of Health Economics, Vol. 22, 2003, pp. 151-185.

Guedj, Ilan, "Ownership vs. Contract: How Vertical Integration Affects Investment Decisions in Pharmaceutical R\&D," MIT working paper, 2004.

Jensen, Michael C., "Agency Costs of Free Cash Flow, Corporate Finance, and Takeovers," American Economic Review, 76, 1986, pp. 323-329.

Khanna, Naveen and Sheri Tice, "The Bright Side of Internal Capital Markets," Journal of Finance, Vol. 56, 2001, pp. 1489-1528.

Lang, Larry H.P., Rene Stulz and Ralph Walkling, “ A Test of the Free Cash flow Hypothesis: The Case of Bidder Returns," Journal of Financial Economics, 29, 1991, pp. 315-335.

Lerner, Josh, Hilary Shane and Alexander Tsai, "Do Equity Financing Cycles Matter?: Evidence from Biotechnology Alliances," Journal of Financial Economics, 67, 2003, pp. 411-446.

Vojislav Maksimovic and Gordon M. Phillips "Do Conglomerate Firms Allocate Resources Inefficiently Across Industries? Theory and Evidence," The Journal of Finance, April, 2002, 721-767.

Myers, Stewart C. and Christopher Howe, "A Life_Cycle Model of Pharmaceutical R\&D," Program on the Pharmaceutical Industry, MIT, Working Paper, 1997.

Rajan, Raghuram; Servaes, Henri and Zingales, Luigi. "The Cost of Diversity: The Diversification Discount and Inefficient Investment." The Journal of Finance, 2000, 55(1), pp. 35-80. 
Roberts, Thomas, et. al., "Trends in the Risks and Benefits to Patients With Cancer Participating in Phase 1 Clinical Trials," The Journal of the American Medical Association, 2004; No. 17, November 3, 292:2130-2140.

Scharfstein, David, "The Dark Side of Internal Capital Markets II: Evidence from Diversified Conglomerates," National Bureau of Economic Research Working Paper 6352, 1998.

Scharfstein, David and Jeremy Stein, "The Dark Side of Internal Capital Markets:

Divisional Rent-Seeking and Inefficient Investment," Journal of Finance, Vol. 55, 2002, pp. 2537-2564.

Shin, Hyun-Han and Rene Stulz, “ Are Internal Capital Markets Efficient?,” Quarterly Journal of Economics, 113, 1998, 531-553.

Stein, Jeremy, "Internal Capital Markets and the Competition for Corporate Resources," Journal of Finance, Vol. 52, 1997, pp. 111-133. 


\section{Table 1}

\section{Sample Construction: Identifying Phase I Clinical Trials}

The initial sample summarized in this table is from Roberts et. al. (2004). It is constructed by searching for Phase I clinical trials listed in annual publications of Papers/Proceedings of the American Society of Clinical Oncology from 1990-2002. For each year, the table lists the number of abstracts identified, the number of abstracts eliminated from the sample for each of the main reasons described in the text, the number of abstracts meeting the selection criteria, and the number of unique drug agents meeting the selection criteria.

\begin{tabular}{|c|c|c|c|c|c|c|c|}
\hline & $\begin{array}{c}\text { Number of } \\
\text { ASCO } \\
\text { Abstracts }\end{array}$ & Radiation & $\begin{array}{c}\text { Chemo- } \\
\text { therapy }\end{array}$ & Pediatrics & $\begin{array}{c}\text { Comb- } \\
\text { ination } \\
\text { Trials }\end{array}$ & $\begin{array}{c}\text { Abstracts } \\
\text { Meeting } \\
\text { Selection } \\
\text { Criteria }\end{array}$ & $\begin{array}{c}\text { Number of } \\
\text { Unique } \\
\text { Agents } \\
\text { Names }\end{array}$ \\
\hline $\mathbf{1 9 9 0}$ & $\mathbf{2 8}$ & 0 & 0 & 0 & 14 & $\mathbf{1 4}$ & $\mathbf{1 2}$ \\
$\mathbf{1 9 9 1}$ & $\mathbf{1 4 2}$ & 3 & 4 & 4 & 62 & $\mathbf{7 3}$ & $\mathbf{2 0}$ \\
$\mathbf{1 9 9 2}$ & $\mathbf{1 7 2}$ & 6 & 9 & 6 & 87 & $\mathbf{7 1}$ & $\mathbf{2 1}$ \\
$\mathbf{1 9 9 3}$ & $\mathbf{1 9 6}$ & 13 & 7 & 7 & 111 & $\mathbf{7 6}$ & $\mathbf{2 7}$ \\
$\mathbf{1 9 9 4}$ & $\mathbf{2 4 0}$ & 11 & 16 & 13 & 123 & $\mathbf{8 9}$ & $\mathbf{2 3}$ \\
$\mathbf{1 9 9 5}$ & $\mathbf{1 6 2}$ & 14 & 8 & 4 & 90 & $\mathbf{6 7}$ & $\mathbf{2 6}$ \\
$\mathbf{1 9 9 6}$ & $\mathbf{1 6 2}$ & 10 & 8 & 5 & 92 & $\mathbf{5 9}$ & $\mathbf{2 7}$ \\
$\mathbf{1 9 9 7}$ & $\mathbf{2 6 3}$ & 25 & 19 & 9 & 112 & $\mathbf{1 1 3}$ & $\mathbf{3 9}$ \\
$\mathbf{1 9 9 8}$ & $\mathbf{2 9 6}$ & 22 & 8 & 9 & 159 & $\mathbf{1 1 5}$ & $\mathbf{5 2}$ \\
$\mathbf{1 9 9 9}$ & $\mathbf{2 8 2}$ & 25 & 12 & 5 & 160 & $\mathbf{1 1 2}$ & $\mathbf{3 4}$ \\
$\mathbf{2 0 0 0}$ & $\mathbf{2 6 1}$ & 20 & 8 & 7 & 141 & $\mathbf{1 0 9}$ & $\mathbf{4 5}$ \\
$\mathbf{2 0 0 1}$ & $\mathbf{2 8 2}$ & 19 & 2 & 4 & 120 & $\mathbf{1 4 9}$ & $\mathbf{2 9}$ \\
$\mathbf{2 0 0 2}$ & $\mathbf{3 1 2}$ & 27 & 8 & 7 & 156 & $\mathbf{1 3 3}$ & $\mathbf{2 2}$ \\
\hline Total & $\mathbf{2 7 9 8}$ & 195 & 109 & 80 & 1427 & $\mathbf{1 1 8 0}$ & $\mathbf{3 7 7}$ \\
\hline
\end{tabular}




\section{Table 2}

\section{Time between Clinical Trials}

This table reports data on the time that elapsed between the initiation of the first Phase I clinical trial and the initiation of the first Phase II clinical trial for a particular agent, as well as information on the time elapsed between Phase II and Phase III.

\section{Panel A: Time Distribution between Clinical Phases (in months)}

\begin{tabular}{|l|c|c|c|c|c|}
\hline & Mean & Median & $\mathbf{2 5 \%}$ & $\mathbf{7 5 \%}$ & St. Dev. \\
\hline \hline Phase I to Phase II & 22.32 & 18 & 11 & 27 & 16.97 \\
\hline Phase II to Phase III & 26.60 & 17 & 12 & 36 & 23.32 \\
\hline
\end{tabular}

\section{Panel B: Time between Clinical Phases}

\begin{tabular}{|c|c|c|c|c|c|}
\hline \multicolumn{3}{|c|}{ Phase I to Phase II } & \multicolumn{3}{c|}{ Phase II to Phase III } \\
\hline Years & Frequency & Percentage & Years & Frequency & Percentage \\
\hline $0-1$ & 59 & $36.4 \%$ & $0-1$ & 10 & $20.0 \%$ \\
$1-2$ & 53 & $32.7 \%$ & $1-2$ & 20 & $40.0 \%$ \\
$2-3$ & 24 & $14.8 \%$ & $2-3$ & 8 & $16.0 \%$ \\
$3-4$ & 12 & $7.4 \%$ & $3-4$ & 4 & $8.0 \%$ \\
$4-5$ & 8 & $4.9 \%$ & $4-5$ & 3 & $6.0 \%$ \\
$5-6$ & 4 & $2.5 \%$ & $5-6$ & 3 & $6.0 \%$ \\
$6-7$ & 0 & $0.0 \%$ & $6-7$ & 1 & $2.0 \%$ \\
$7-8$ & 1 & $0.6 \%$ & $7-8$ & 0 & $0.0 \%$ \\
$8-9$ & 1 & $0.6 \%$ & $8-9$ & 0 & $0.0 \%$ \\
$9-10$ & 0 & $0.0 \%$ & $9-10$ & 0 & $0.0 \%$ \\
$10-11$ & 0 & $0.0 \%$ & $10-11$ & 1 & $2.0 \%$ \\
\hline Total & $\mathbf{1 6 2}$ & & Total & $\mathbf{5 0}$ & \\
\hline
\end{tabular}

Panel C: Percentage of the sample moving to the next clinical phase

\begin{tabular}{|l|c|c|c|}
\hline & $\begin{array}{c}\text { In 2 } \\
\text { years }\end{array}$ & $\begin{array}{c}\text { In 3 } \\
\text { years }\end{array}$ & Ever \\
\hline From Phase I to Phase II & $48 \%$ & $58 \%$ & $69 \%$ \\
\hline From Phase II to Phase III & $19 \%$ & $24 \%$ & $31 \%$ \\
\hline
\end{tabular}


Table 3

Agents per Company and Indications per Agent

This table reports summary statistics of the number of agents developed by companies and the number of indications (different types of cancer) investigated for each drug developed.

Panel A: Number of Agents per Sponsor

\begin{tabular}{|c|c|c|}
\hline $\begin{array}{c}\text { Number of } \\
\text { Agents }\end{array}$ & Frequency & Percentage \\
\hline \hline 1 & 103 & $57 \%$ \\
2 & 43 & $24 \%$ \\
3 & 13 & $7 \%$ \\
4 & 7 & $4 \%$ \\
5 & 4 & $2 \%$ \\
6 & 5 & $3 \%$ \\
7 & 0 & $0 \%$ \\
8 & 2 & $1 \%$ \\
9 & 0 & $0 \%$ \\
10 & 1 & $1 \%$ \\
11 & 0 & $0 \%$ \\
12 & 0 & $0 \%$ \\
13 & 1 & $1 \%$ \\
14 & 0 & $0 \%$ \\
15 & 0 & $0 \%$ \\
16 & 2 & $1 \%$ \\
\hline Total & 181 & \\
\hline
\end{tabular}

Panel B: Number of Phase II Indications per Agent

\begin{tabular}{|c|c|c|}
\hline Number of Indications & Frequency & Percentage \\
\hline \hline 1 & 83 & $46 \%$ \\
2 & 31 & $17 \%$ \\
3 & 22 & $12 \%$ \\
4 & 14 & $8 \%$ \\
5 & 9 & $5 \%$ \\
6 & 9 & $5 \%$ \\
7 & 5 & $3 \%$ \\
8 & 3 & $2 \%$ \\
9 & 3 & $2 \%$ \\
14 & 1 & $1 \%$ \\
\hline Total & 180 & \\
\hline
\end{tabular}


Table 4

\section{Summary Statistics on Sample Companies}

This table report summary statistics on the public companies in our sample. We use Standard \& Poor's Compustat, Compustat Canada, and Compustat Global Industrial/Commercial. For comparability, all the financial numbers are converted to million U.S. Dollars deflated to the year 2000. All the figures are for the year in which each drug went to Phase I clinical trials. Revenues, Assets, Cash, R\&D, and Book Value are from the respective items in Compustat. Market Cap is the number of outstanding shares at the end of the calendar year multiplied by the share price at the end of the calendar year. Q is defined as the ratio of the market value of equity plus the book value of assets less the book value of equity to the book value of assets. Panel A reports the full sample; Panel B reports the sub-sample of mature firms; and Panel C reports the complimentary sub-sample of early-stage firms. We define an early stage firm as one with revenues less than or equal to $\$ 30$ million deflated to the year 2000.

\begin{tabular}{|c|c|c|c|c|c|c|c|c|}
\hline Statistics & $\begin{array}{c}\text { Years } \\
\text { Since } \\
\text { Public }\end{array}$ & Revenues & Assets & Cash & R\&D & $\begin{array}{c}\text { Market } \\
\text { Cap }\end{array}$ & $\begin{array}{c}\text { Book } \\
\text { Value }\end{array}$ & $\mathbf{Q}$ \\
\hline \hline Mean & 25.8 & $8,116.9$ & $10,964.5$ & $1,947.0$ & $1,003.9$ & $38,635.2$ & $5,282.3$ & 10.2 \\
Median & 21.7 & $5,761.7$ & $4,544.9$ & 452.1 & 394.5 & $10,310.8$ & $1,563.4$ & 7.4 \\
St. Dev. & 22.7 & $9,766.1$ & $13,531.1$ & $3,257.8$ & $1,228.8$ & $54,844.1$ & $7,001.9$ & 10.5 \\
\hline $\mathbf{1 \%}$ & 0.2 & 0.0 & 4.0 & 2.8 & 2.7 & 14.4 & 1.6 & 1.3 \\
$\mathbf{2 5 \%}$ & 4.2 & 9.5 & 57.5 & 41.4 & 21.0 & 202.7 & 45.7 & 4.4 \\
$\mathbf{7 5 \%}$ & 40.7 & $14,080.2$ & $17,578.0$ & $2,469.1$ & $1,798.9$ & $60,107.2$ & $8,678.8$ & 12.7 \\
$\mathbf{9 9 \%}$ & 73.4 & $33,822.0$ & $45,561.8$ & $12,959.5$ & $4,879.3$ & $246,316.3$ & $26,140.6$ & 64.4 \\
\hline
\end{tabular}

Panel B: Mature Firms

\begin{tabular}{|c|c|c|c|c|c|c|c|c|}
\hline Statistics & $\begin{array}{c}\text { Years } \\
\text { Since } \\
\text { Public }\end{array}$ & Revenues & Assets & Cash & R\&D & $\begin{array}{c}\text { Market } \\
\text { Cap }\end{array}$ & $\begin{array}{c}\text { Book } \\
\text { Value }\end{array}$ & $\mathbf{Q}$ \\
\hline \hline Mean & 37.4 & $14,178.9$ & $19,084.5$ & $3,340.1$ & $1,736.8$ & $67,134.8$ & $9,172.7$ & 10.5 \\
Median & 37.9 & $13,488.5$ & $16,543.5$ & $2,184.0$ & $1,635.0$ & $55,626.0$ & $7,344.0$ & 8.1 \\
St. Dev. & 21.4 & $8,982.5$ & $12,874.0$ & $3,745.6$ & $1,175.6$ & $57,889.4$ & $7,092.6$ & 7.3 \\
\hline $\mathbf{1 \%}$ & 1.0 & 89.1 & 114.5 & 73.8 & 15.0 & 932.6 & 93.8 & 2.4 \\
$\mathbf{2 5 \%}$ & 24.0 & $7,683.0$ & $9,288.8$ & 775.5 & 847.9 & $23,310.1$ & $4,557.5$ & 6.5 \\
$\mathbf{7 5 \%}$ & 56.3 & $18,216.0$ & $29,971.0$ & $3,836.8$ & $2,445.9$ & $92,310.5$ & $11,913.0$ & 13.7 \\
$\mathbf{9 9 \%}$ & $\mathbf{7 3 . 5}$ & $37,899.1$ & $47,542.3$ & $15,602.2$ & $4,879.3$ & $246,316.3$ & $26,140.6$ & 35.8 \\
\hline
\end{tabular}

Panel C: Early Stage Firms

\begin{tabular}{|c|c|c|c|c|c|c|c|c|}
\hline Statistics & $\begin{array}{c}\text { Years } \\
\text { Since } \\
\text { Public }\end{array}$ & Revenues & Assets & Cash & R\&D & $\begin{array}{c}\text { Market } \\
\text { Cap }\end{array}$ & $\begin{array}{c}\text { Book } \\
\text { Value }\end{array}$ & $\mathbf{Q}$ \\
\hline \hline Mean & 10.2 & 10.7 & 106.3 & 84.1 & 23.9 & 404.0 & 78.9 & 9.7 \\
Median & 5.0 & 7.1 & 51.1 & 35.2 & 18.3 & 176.4 & 41.6 & 5.2 \\
St. Dev. & 12.9 & 11.6 & 156.9 & 142.1 & 26.3 & 581.4 & 120.3 & 13.8 \\
\hline $\mathbf{1 \%}$ & 0.1 & 0.0 & 2.9 & 0.4 & 2.5 & 0.5 & 0.8 & 1.3 \\
$\mathbf{2 5 \%}$ & 1.3 & 1.8 & 24.9 & 17.8 & 10.4 & 72.4 & 18.1 & 3.0 \\
$\mathbf{7 5 \%}$ & 12.0 & 17.5 & 114.4 & 82.3 & 29.9 & 463.2 & 86.5 & 9.2 \\
$\mathbf{9 9 \%}$ & 42.4 & 28.1 & 793.7 & 788.5 & 223.5 & $2,893.8$ & 541.4 & 74.2 \\
\hline
\end{tabular}




\section{Table 5 \\ Probit Regressions of the Probability of Moving from Phase I to Phase II}

This table reports the result of probit regressions. The dependent variable takes the value 1 if the firm progresses to Phase II trials within two years of initiating a Phase I trial and 0 otherwise. The regressors include a dummy variable which takes the value one if the company is an early stage company (revenues no more than $\$ 30$ million deflated to the year 2000). The regressors also include a set of controls for clinical results of the Phase I trials, as well as characteristics of the drug in development. Response Rate I is the percentage of patients whose tumor shrank in the Phase II trials. Toxicity is the percentage of patients who had a toxic reaction to the drug in the Phase I trials. Biologic is a dummy variable that equals 1 if the drug is a biologic drug, 0 if it is a chemical drug. NIH Sponsored is a dummy variable that equals 1 if the National Institutes of Health (NIH) or any of its affiliate institutes such as the National Cancer Institute (NCI) sponsored the drug. The regressions also control for the potential financial profit to be expected from the development of the drugs. One of the controls is the PharmaProjects' estimated market size of the targeted indication. We use two dummy variables, one for whether the estimated market size is between \$500 million and \$2000 million and another for whether the estimated market size exceeds \$2000 million. Another control measures the novelty of the drugs. We measure this by recording the pharmacological description (a drug's mechanism of action in the body through which it exerts its therapeutic effect) and ranking the drug by the number of drugs developed for cancer with the same pharmacological description prior to this drug. Novelty is the log of the inverse of this rank.

\begin{tabular}{lcccc} 
& $(1)$ & $(2)$ & $(3)$ & $(4)$ \\
\hline Early Stage (dummy) & 0.1613 & 0.1649 & 0.1600 & 0.1655 \\
& $(2.83)$ & $(3.17)$ & $(2.70)$ & $(3.01)$ \\
Response Rate I (percentage) & & & & 1.1972 \\
& & 0.9721 & & $(1.04)$ \\
Toxicity (percentage) & $(0.90)$ & & -5.6069 \\
& & -4.9275 & & $(0.59)$ \\
Biologic (dummy) & $(0.57)$ & & -0.0668 \\
& -0.0274 & & $(0.41)$ \\
NIH Sponsored (dummy) & $(0.19)$ & & 0.2638 \\
& & 0.1929 & & $(1.67)$ \\
Market Size - 500-2000\$m (dummy) & & $(1.14)$ & & 0.2005 \\
& & & 0.2026 & $(1.43)$ \\
Market Size - 2000+\$m (dummy) & & & $(1.49)$ & 0.0499 \\
Novelty & & 0.0605 & $(0.37)$ \\
& & & $(0.46)$ & 0.0957 \\
Number of Observations & & 0.0896 & $(5.45)$ \\
\hline
\end{tabular}

Note: We report the change in the probability for an infinitesimal change in each independent, continuous variable and, by default, the discrete change in the probability for dummy variables. In parenthesis are the Z-stats calculated using White (1982) standard errors. We cluster around the phase I year. 


\section{Table 6 \\ Summary Statistics of Phase II Clinical Data}

This table reports summary statistics on the clinical data collected from the Papers/Proceedings of the American Society of Clinical Oncology (ASCO) from 1990-2002. If a drug had more than one Phase II trial for a particular indication we weight the results by the number of effective patients in each clinical trial. There are 11 categories of indications derived from the American Cancer Society. Response Rate is the percentage of patients whose tumor shrank in the Phase II trials. Previous Treatments is the number of previous treatments the patients in the trial have had prior to joining the trial.

\section{Panel A: Tumor Response Rates}

\begin{tabular}{c|c|c|c}
\hline Response Rate & Full Sample & Early Stage Companies & Mature Companies \\
\hline \hline \multicolumn{4}{c}{ Full Sample } \\
\hline \hline Mean & 0.095 & 0.061 & 0.120 \\
Median & 0.040 & 0.030 & 0.065 \\
Std & 0.133 & 0.076 & 0.159 \\
\% Greater than 0 & $67 \%$ & $65 \%$ & $70 \%$ \\
\hline \hline
\end{tabular}

Panel B: Phase II Indications

\begin{tabular}{l|c|c|c}
\hline Indication & Full Sample & $\begin{array}{c}\text { Early Stage } \\
\text { Companies }\end{array}$ & $\begin{array}{c}\text { Mature } \\
\text { Companies }\end{array}$ \\
\hline \hline Bone & $1 \%$ & $1 \%$ & $0 \%$ \\
Brain \& Nervous systems & $3 \%$ & $3 \%$ & $3 \%$ \\
Breast & $14 \%$ & $10 \%$ & $17 \%$ \\
Digestive & $20 \%$ & $22 \%$ & $18 \%$ \\
Genital & $14 \%$ & $14 \%$ & $14 \%$ \\
Head and Neck & $3 \%$ & $3 \%$ & $3 \%$ \\
Leukemia & $1 \%$ & $2 \%$ & $0 \%$ \\
Lymphoma & $6 \%$ & $7 \%$ & $5 \%$ \\
Respiratory & $20 \%$ & $21 \%$ & $20 \%$ \\
Skin & $7 \%$ & $8 \%$ & $6 \%$ \\
Urinary & $10 \%$ & $7 \%$ & $12 \%$ \\
Other & $1 \%$ & $0 \%$ & $1 \%$ \\
\hline
\end{tabular}

Panel C: Trial Patients with Previous Treatments

\begin{tabular}{l|c|c|c}
\hline $\begin{array}{l}\text { Previous } \\
\text { Treatments }\end{array}$ & Full Sample & $\begin{array}{c}\text { Early Stage } \\
\text { Companies }\end{array}$ & $\begin{array}{c}\text { Mature } \\
\text { Companies }\end{array}$ \\
\hline \hline None & $25.87 \%$ & $25.58 \%$ & $26.09 \%$ \\
$\mathbf{1}$ & $21.39 \%$ & $17.44 \%$ & $24.35 \%$ \\
$\mathbf{2}$ & $9.95 \%$ & $10.47 \%$ & $9.57 \%$ \\
$\mathbf{2 +}$ & $41.29 \%$ & $46.51 \%$ & $37.39 \%$ \\
\hline
\end{tabular}




\section{Table 7 \\ Regressions of the Response Rates of Patients in Phase II Clinical Trials}

The dependent variable is Response Rate, the percentage of patients in a Phase II trial whose tumors shrank. These data are taken from Papers/Proceedings of the American Society of Clinical Oncology (ASCO) from 1990-2002. If more than one trial was undertaken for a certain indication, we average them, weighting by the number of patients. Because indications have different baseline response rate, we control for each indication by including indication dummies based on categories of the American Cancer Society. We also control for the number of previous treatments the patients received prior to joining the trial, and for the stage of the cancer the patient is in. Columns (1), (2), and (3) use the sub-sample of public firms that moved to Phase II within 2 years of starting Phase I trials. Column (3) uses the full sample. In parenthesis are the t-stats calculated using White (1982) standard errors.

\begin{tabular}{lcccc} 
& $(1)$ & $(2)$ & $(3)$ & $(4)$ \\
\hline Early Stage (dummy) & -0.0442 & -0.0589 & -0.0646 & -0.0615 \\
& $(1.44)$ & $(2.24)$ & $(2.38)$ & $(3.53)$ \\
Market Size - 500-2000\$m (dummy) & & & 0.0020 & 0.0502 \\
Market Size - 2000+\$m (dummy) & & $(0.03)$ & $(1.12)$ \\
Novelty & & 0.0165 & 0.0340 \\
& No & & $(0.26)$ & $(0.96)$ \\
Indication Dummies & Yes & -0.0107 & -0.0103 \\
Previous Treatment Dummies & No & Yes & Yes & Yes \\
Disease Stage Dummies & No & Yes & Yes & Yes \\
$\mathrm{R}^{2}$ & & & & Yes \\
Number of Observations & 0.02 & 0.29 & 0.30 & 0.27 \\
\hline
\end{tabular}




\section{Table 8 \\ Probit Regressions of the Probability of Moving from Phase II to Phase III for the Drugs Candidates that Moved to Phase II}

This table reports the result of probit regressions. The dependent variable takes the value 1 if the firm progresses to Phase III trials within two years of initiating a Phase II trial and 0 otherwise. The regressors include a dummy variable which takes the value one if the company is an early stage company (revenues less than \$30 million deflated to the year 2000). The regressors also include a set of controls for the characteristics of the drug in development. One of the controls is the PharmaProjects' estimated market size of the targeted indication. We use two dummy variables, one for whether the estimated market size is between $\$ 500$ million and \$2000 million and another for whether the estimated market size exceeds \$2000 million. Another control measures the novelty of the drugs. We measure this by recording the pharmacological description (a drug's mechanism of action in the body, through which it exerts its therapeutic effect) and ranking the drug by the number of drugs developed for cancer with the same pharmacological description prior to this drug. Novelty is the log of the inverse of this rank.

\begin{tabular}{lcc} 
& $(1)$ & $(2)$ \\
\hline Early Stage (dummy) & -0.2136 & -0.1931 \\
& $(2.79)$ & $(2.46)$ \\
Market Size - 500-2000\$m (dummy) & & 0.2057 \\
& & $(0.76)$ \\
Market Size - 2000+\$m (dummy) & & 0.0276 \\
Novelty & & $(0.12)$ \\
& & 0.0618 \\
Number of Observations & & $(2.74)$ \\
\hline
\end{tabular}

Note: We report the change in the probability for an infinitesimal change in each independent, continuous variable and, by default, the discrete change in the probability for dummy variables. In parenthesis are the Z-stats calculated using White (1982) standard errors. We cluster around the phase I year. 
Table 9

\section{Current Status of the Drugs}

This table reports the current status of the drugs in our sample according to PharmaProjects. NDR - No Development Reported, is the status assigned by The PharmaProjects when there is no information about a drug and it seems the drug is not under development anymore (although the company has not officially announced that the drug has been discontinued). Discontinued refers to drugs for which the company has announced that it has ceased development. Pre-Registration refers to drugs for which the company is in the process of filing a NDA (New Drug Application) with the FDA (Food and Drug Administration) or has announced that it intends to do so . Launched drugs are those drugs that have been approved by the FDA and are on the market. Panel A reports the statistics for all the drugs; Panel B reports the statistics for the drugs that have moved to Phase II within two years of Phase I initiation.

\section{PANEL A: All the drugs}

\begin{tabular}{|l|c|c|c|c|c|c|}
\hline & \multicolumn{2}{|c|}{ All } & \multicolumn{2}{c|}{ Mature Companies } & \multicolumn{2}{c|}{ Early Stage Companies } \\
\hline Status & Frequency & Percentage & Frequency & Percentage & Frequency & Percentage \\
\hline NDR & 53 & $22.55 \%$ & 38 & $27.34 \%$ & 15 & $15.63 \%$ \\
Discontinued & 31 & $13.19 \%$ & 22 & $15.83 \%$ & 9 & $9.38 \%$ \\
Phase I & 25 & $10.64 \%$ & 15 & $10.79 \%$ & 10 & $10.42 \%$ \\
Phase II & 67 & $28.51 \%$ & 27 & $19.42 \%$ & 40 & $41.67 \%$ \\
Phase III & 27 & $11.49 \%$ & 16 & $11.51 \%$ & 11 & $11.46 \%$ \\
Pre-Registration & 5 & $2.13 \%$ & 0 & $0.00 \%$ & 5 & $5.21 \%$ \\
Launched & 27 & $11.49 \%$ & 21 & $15.11 \%$ & 6 & $6.25 \%$ \\
\hline & 235 & & 139 & & 96 & \\
\hline
\end{tabular}

PANEL B: Drugs that Moved to Phase II in 2 Years or Less

\begin{tabular}{|l|c|c|c|c|c|c|}
\hline & \multicolumn{2}{|c|}{ All } & \multicolumn{2}{c|}{ Mature Companies } & \multicolumn{2}{c|}{ Early Stage Companies } \\
\hline Status & Frequency & Percentage & Frequency & Percentage & Frequency & Percentage \\
\hline NDR & 18 & $14.75 \%$ & 9 & $14.29 \%$ & 9 & $15.25 \%$ \\
Discontinued & 12 & $9.84 \%$ & 6 & $9.52 \%$ & 6 & $10.17 \%$ \\
Phase I & 1 & $0.82 \%$ & 20 & $31.75 \%$ & 1 & $1.69 \%$ \\
Phase II & 44 & $36.07 \%$ & 10 & $15.87 \%$ & 24 & $40.68 \%$ \\
Phase III & 20 & $16.39 \%$ & 0 & $0.00 \%$ & 10 & $16.95 \%$ \\
Pre-Registration & 4 & $3.28 \%$ & 0 & $0.00 \%$ & 4 & $6.78 \%$ \\
Launched & 23 & $18.85 \%$ & 18 & $28.57 \%$ & 5 & $8.47 \%$ \\
\hline & 122 & & 63 & & 59 & \\
\hline
\end{tabular}




\section{Table 10}

\section{Sales of Approved Drugs}

This table reports the sales of the drugs in the sample that were approved. The source of the data is New Medicine's Oncology KnowledgeBASE. All the sales figures are in Millions of US Dollars deflated to year 2000 values. The numbers are for the first, second, and third year of sales following FDA approval. Out of the 29 drugs approved in the sample, this table is based on data on 23 of those drugs, 17 out of the 22 approved drugs originated by mature companies and all the 7 approved drugs originated by early stage companies.

\begin{tabular}{l|c|c|c|c|c}
\hline & Mean & Median & St. Dev. & Min & Max \\
\hline \multicolumn{7}{l|}{ First Year Sales } & \multicolumn{1}{l}{} \\
\hline Mature Companies & 99.7 & 62.3 & 108.9 & 0.9 & 441.8 \\
\hline Early Stage Companies & 12.7 & 6.0 & 17.1 & 1.4 & 56.4 \\
\hline \\
Second Year Sales \\
\hline Mature Companies & 141.6 & 98.2 & 144.7 & 5.0 & 590.4 \\
\hline Early Stage Companies & 60.3 & 15.0 & 72.9 & 2.6 & 176.1 \\
\hline \hline
\end{tabular}

Third Year Sales

\begin{tabular}{l|c|c|c|c|c}
\hline \hline Mature Companies & 199.4 & 145.4 & 196.0 & 5.0 & 718.9 \\
\hline Early Stage Companies & 108.5 & 20.8 & 135.6 & 6.5 & 339.4 \\
\hline
\end{tabular}




\title{
Table 11 \\ Probit Regressions of the Probability of Moving from Phase I to Phase II
}

This table reports the result of probit regressions. The dependent variable takes the value 1 if the firm progresses to Phase II trials within two years of initiating a Phase I trial and 0 otherwise. The regressors include a dummy variable which takes the value one if the company is an early stage company (revenues no more than $\$ 30$ million deflated to the year 2000) and is financially constrained (cash of less than $\$ 30$ million deflated to the year 2000). We also include a dummy for early stage companies that are not financially constrained (those early stage companies with more that $\$ 30$ million of cash deflated to the year 2000). The regressors also include a set of controls for clinical results of the Phase I trials, as well as characteristics of the drug in development. Response Rate $I$ is the percentage of patients whose tumor shrank in the Phase II trials. Toxicity is the percentage of patients who had a toxic reaction to the drug in the Phase I trials. Biologic is a dummy variable that equals 1 if the drug is a biologic drug, 0 if it is a chemical drug. NIH Sponsored is a dummy variable that equals 1 if the National Institutes of Health (NIH) or any of its affiliate institutes such as the National Cancer Institute (NCI) sponsored the drug. The regressions also control for the potential financial profit to be expected from the development of the drugs. One of the controls is the PharmaProjects' estimated market size of the targeted indication. We use two dummy variables, one for whether the estimated market size is between $\$ 500$ million and $\$ 2000$ million and another for whether the estimated market size exceeds \$2000 million. Another control measures the novelty of the drugs. We measure this by recording the pharmacological description (a drug's mechanism of action in the body, through which it exerts its therapeutic effect) and ranking the drug by the number of drugs developed for cancer with the same pharmacological description prior to this drug. Novelty is the log of the inverse of this rank.

Early Stage High Cash Firm (dummy)

Early Stage Low Cash Firm (dummy)

Response Rate (percentage)

Toxicity (percentage)

Biologic (dummy)

Market Size - 500-2000\$m (dummy)

Market Size - 2000+\$m (dummy)

Novelty

$\begin{array}{ll}\text { NIH Sponsored (dummy) } & 0.1930 \\ & (1.02)\end{array}$

$(1)$

(2)

0.3165

0.0557
0.0508

1.0887

$-7.6176$

$(0.87)$

$-0.0398$

$\begin{array}{ll}\text { NIH Sponsored (dummy) } & 0.1930 \\ & (1.02)\end{array}$

(1)

$(1.49)$

\begin{tabular}{lcc} 
Market Size - 500-2000\$m (dummy) & 0.1634 & 0.1574 \\
Market Size - 2000+\$m (dummy) & $(1.06)$ & $(0.99)$ \\
& 0.0072 & -0.0071 \\
Novelty & $(0.05)$ & $(0.05)$ \\
& 0.0832 & 0.0881 \\
Number of Observations & $(4.70)$ & $(4.46)$ \\
\hline
\end{tabular}

Note: We report the change in the probability for an infinitesimal change in each independent, continuous variable and, by default, the discrete change in the probability for dummy variables. In parenthesis are the z-stats calculated using White (1982) standard errors. We cluster around the Phase I year. 


\section{Table 12}

\section{Regressions of the Response Rate of Patients in Phase II Clinical Trials}

The dependent variable is Response Rate, the percentage of patients in a Phase II trial whose tumors shrank. These data are taken from Papers/Proceedings of the American Society of Clinical Oncology (ASCO) from 1990-2002. If more than one trial was undertaken for a certain indication, we average them, weighting by the number of patients. Because indications have different baseline response rate, we control for each indication by including indication dummies based on categories of the American Cancer Society. We also control for the number of previous treatments the patients received prior to joining the trial, and for the stage of the cancer the patient is in. Columns (1), (2), and (3) use the sub-sample of public firms that moved to Phase II within 2 years of starting Phase I trials. Column (3) uses the full sample. In parenthesis are the t-stats calculated using White (1982) standard errors.

\begin{tabular}{lcccc} 
& $(1)$ & $(2)$ & $(3)$ & $(4)$ \\
\hline Early Stage High Cash Firm (dummy) & -0.0551 & -0.0889 & -0.0934 & -0.0609 \\
Early Stage Low Cash Firm (dummy) & $(1.73)$ & $(3.71)$ & $(4.20)$ & $(.48)$ \\
& -0.0364 & -0.0397 & -0.0466 & -0.0147 \\
Market Size - 500-2000\$m (dummy) & $(1.07)$ & $(1.33)$ & $(1.46)$ & $(1.50)$ \\
Market Size - 2000+\$m (dummy) & & -0.0138 & 0.0383 \\
Novelty & & & $(0.20)$ & $(0.89)$ \\
& & & 0.0000 & 0.0207 \\
Indication Dummies & No & Yes & Yes & Yes \\
Previous Treatment Dummies & No & Yes & Yes & Yes \\
Disease Stage Dummies & No & Yes & Yes & Yes \\
$\mathrm{R}^{2}$ & & & $(2.25)$ & $(2.28)$ \\
Number of Observations & 0.02 & 0.30 & 0.31 & 0.28 \\
\hline
\end{tabular}




\section{Table 13}

\section{Probit Regressions of the Probability of Moving from Phase II to Phase III}

The model estimated is a probit model. The dependent variable is the probability of advancing from phase II to phase III in the 3 years following phase II, thus it takes one of two values: 1 if the drug moved to phase II and 0 if not. We define an early stage company as one that has revenues (deflated to the year 2000) of less than $30 \$ \mathrm{~m}$. We define a financially constrained company as one that has less than $30 \$ \mathrm{~m}$ in cash and short-term investments (Deflated to the year 2000). We regress this probability on a dummy if the company is an early stage company and not financially constrained and on another dummy if it is an early stage company that is financially constrained. Market size - We use 3 dummies whether the potential market size is up to $500 \$ \mathrm{~m}$, between 500 and $2000 \$ \mathrm{~m}$ and more than $2000 \$ \mathrm{~m}$. Novelty of the drugs - for every drug we record its pharmacological description (a drug's mechanism of action in the body, through which it exerts its therapeutic effect) and rank the drug by the number of drugs developed for cancer with the same pharmacological description prior to this drug. Novelty is the log of the inverse of this rank.

\begin{tabular}{lcc} 
& $(1)$ & $(2)$ \\
\hline Early Stage High Cash Firm (dummy) & -0.2974 & -0.2903 \\
Early Stage Low Cash Firm (dummy) & $(3.28)$ & $(3.54)$ \\
& -0.0762 & $(0.05)$ \\
Market Size - 500-2000\$m (dummy) & $(1.02)$ & $(0.67)$ \\
& & \\
Market Size - 2000+\$m (dummy) & 0.3092 \\
Novelty & $(1.14)$ \\
& & 0.0918 \\
Number of Observations & $(0.46)$ \\
\end{tabular}

Note: We report the change in the probability for an infinitesimal change in each independent, continuous variable and, by default, the discrete change in the probability for dummy variables. In parenthesis are the Z-stats calculated using White (1982) standard errors. We cluster around the Phase I year. 
Table 14

Cox Proportional Hazard Model

We use a Cox proportional hazard model, following the specification outlined in Cox (1975) as a methodology developed to analyze survival data. We do so in order to account for the possible right censoring in our data. A drug is assumed to have a certain probability of succeeding in each period. Success is defined as the event of moving from phase I to phase II, or the event of moving from phase II to phase III. The instantaneous probability of success at any given time $t$ is called the hazard rate, $h(t)$, defined as:

$$
h(t)=\frac{\text { Probability of success between } t \text { and } \Delta t}{\text { Probability of success } \geq t}
$$

The Cox model assumes that the hazard function has a functional form, yet the model assumes no restriction on the function. Thus, the dependent variable is time to the defined outcome.

We use the same variables and controls as described the earlier tables.

\begin{tabular}{|c|c|c|c|c|}
\hline & $\begin{array}{l}\text { Advan } \\
\text { phase I }\end{array}$ & $\begin{array}{l}\text { from } \\
\text { hase II }\end{array}$ & $\begin{array}{l}\text { Advar } \\
\text { phase I }\end{array}$ & $\begin{array}{l}\text { from } \\
\text { hase III }\end{array}$ \\
\hline & (1) & (2) & (3) & (4) \\
\hline Early Stage (dummy) & 1.5790 & & 0.3946 & \\
\hline & (3.43) & & $(2.78)$ & \\
\hline Early Stage High Cash Firm (dummy) & & 2.2269 & & 0.3452 \\
\hline & & $(4.71)$ & & (2.88) \\
\hline Early Stage Low Cash Firm (dummy) & & 1.2401 & & 0.4487 \\
\hline & & $(1.49)$ & & $(1.76)$ \\
\hline Response Rate (percentage) & 0.0865 & 0.1112 & & \\
\hline & (1.48) & (1.34) & & \\
\hline Biologic (dummy) & 0.9413 & 1.0049 & & \\
\hline & $(0.22)$ & (0.02) & & \\
\hline NIH Sponsored (dummy) & 1.8109 & 1.8232 & & \\
\hline & $(1.35)$ & $(1.27)$ & & \\
\hline Market Size - 500-2000\$m (dummy) & 1.7818 & 1.5736 & 1.1652 & 1.2211 \\
\hline & $(1.61)$ & $(1.21)$ & $(0.22)$ & $(0.29)$ \\
\hline Market Size - 2000+\$m (dummy) & 1.373 & 1.1765 & 0.6158 & 0.6526 \\
\hline & $(0.97)$ & $(0.47)$ & $(0.61)$ & $(0.54)$ \\
\hline Novelty & 1.1246 & 1.0957 & 1.2773 & 1.2881 \\
\hline & $(1.80)$ & $(1.23)$ & $(1.55)$ & $(1.65)$ \\
\hline Number of Observations & 235 & 235 & 162 & 162 \\
\hline
\end{tabular}

Note: We report the hazard rate for an infinitesimal change in time. In parenthesis are the z-stats calculated using White (1982) standard errors. 